\title{
Role of Copeptin in predicting of Major Adverse Cardiovascular Events (MACE) during Hospitalization on Acute Myocardial Infarction Patients
}

\author{
Trisulo Wasyanto'), I Putu Raynantha'), Ahmad Yasa' ${ }^{1)}$ \\ 1)Department of Cardiology and Vascular Medicine, Faculty of Medicine, \\ Universitas Sebelas Maret/Dr. Moewardi Hospital, Surakarta \\ 2)Department of Cardiology and Vascular Medicine, Faculty of Medicine, \\ Universitas Sebelas Maret
}

\section{ABSTRACT}

Background: Copeptin has been considered as a potential biomarker for AMI which also give information regarding the prognostic of the Acute myocardial infarction (AMI). The aim of this study is to understand the role of copeptin as a predictor of major adverse cardiovascular events (MACE) during hospitalization in AMI patients.

Subjects and Method: This was a cohort analytical study conducted at Dr. Moewardi Hospital, Surakarta, from March to May 2021. The dependent variable was MACE. The independent variable was the copeptin level. We observe the MACE during hospitalization and analyze the cut-off point value for optimal copeptin levels to predict the occurrence of MACE using the receiver operating characteristic (ROC) curve. Linear multiple regression was conducted to predict determinants of MACE in hospitalization patients.

Results: 52 patients recruited in this research (44 males, 8 females). During hospitalization, MACE occurred in $52 \%$ of these subjects, with the respective proportions for acute heart failure, cardiogenic shock, arrhythmias, cardiopulmonary resuscitation, and mortality of $28 \%$, $10 \%, 8 \%, 4 \%$, and $2 \%$. The ROC curve showed that the cut-off point of copeptin was 2,141.50 $\mathrm{pg} / \mathrm{mL}$ and area under curve (AUC) value of 0.710 with sensitivity of $75.0 \%$, specificity of $68.80 \%$ and accuracy of $71.15 \%$. Hence, the AUC values and accuracy present fair results for predicting MACE during hospitalization in AMI patients.

Conclusion: Copeptin has a role as a predicttor of MACE during hospitalization in AMI patients.

Keywords: copeptin, mayor adverse cardiovascular events, acute myocardial infarction

\section{Correspondence:}

Trisulo Wasyanto. Department of Cardiology and Vascular Medicine, Faculty of Medicine, Universitas Sebelas Maret/ Dr. Moewardi Hospital. Jl. Kol. Sutarto 132, Surakarta 57126, Central Java. Email: trisulo.wasyanto@gmail.com.

\section{Cite this as:}

Wasyanto T, Raynantha IP, Yasa A (2021). Role of Copeptin in predicting of Major Adverse Cardiovascular Events (MACE) during Hospitalization on Acute Myocardial Infarction Patients. Indones J Med. 06(02): 230-238. https://doi.org/10.26911/theijmed.2021.06.02.12.

cc (i) (-) Indonesian Journal of Medicine is licensed under a Creative Commons

EY NC SA Attribution-Non Commercial-Share Alike 4.0 International License.

\section{BACKGROUND}

Cardiovascular disease is still the leading cause of death in the world and a burden and obstacle to sustainable human development (Roth et al., 2017). One of them is coronary heart disease (CHD) which is a form of heart disease caused by narrowing of the coronary arteries that provide blood flow to the heart. CHD can be termed as acute coronary syndrome (ACS) (Braunwald et al., 2019). Estimates of the incidence of acute myocardial infarction (AMI) in the United States are still quite high, with 605,000 new attacks and 200 
thousand repeated attacks per year (Virani et al., 2021). The prevalence and incidence of heart attacks are also quite high in Indonesia, where data from Dr. Moewardi hospital, Surakarta in 2014-2018 there were $62.1 \%$ of cases of ST-segment elevation myocardial infarction (STEMI) and 20.4\% of cases of non-ST-segment elevation myocardial infarction (NSTEMI). Data were also obtained where the main mortality in patients with AMI was cardiogenic shock (59.9\%) and ventricular arrhythmias (25\%) (Wasyanto and Tridamayanti, 2019).

In AMI attacks, there is a disturbance in the balance of homeostasis, and causes stress to the patient. Stressors can activate the hypothalamic-pituitary-adrenal (HPA) axis and increase the concentration of adrenal hormones. Arginine vasopressin (AVP) is a major HPA hormone that is stimulated by this stressor. AVP increases in response to various types of stress, both physical and emotional, as well as in sepsis, hypotension, dehydration, heart problems, and lower respiratory tract infections and in acute shortness of breath (Nickel et al., 2012). Copeptin is a glycosylated polypeptide from the cleavage of the AVP precursor (Parizadeh et al., 2018).

Copeptin is released in an amount ratio proportional to AVP and is more stable in the circulation and is easily measured in concentration. Copeptin has been considered as a potential biomarker for ACS (Katan and Crain, 2010). These copeptin biomarkers increase the value of prognostic information from various clinical assessments of AMI patients (Von Haehling et al., 2012).

Currently, there are no studies that specifically examine the role of copeptin as a predictor of major adverse cardiovascular events (MACE) in AMI patients. Based on this, the researchers wanted to know whether copeptin can be used as a predictor of MACE during hospitalization in AMI patients.

\section{SUBJECTS AND METHOD}

\section{Study Design}

This prospective observational cohort analytic study to determine the role of copeptin as a predictor of MACE during hospitalizetion in AMI patients. The study was conducted at the Emergency Room and Intensive Cardiovascular Care Unit (ICVCU) at Dr. Moewardi Hospital Surakarta in AMI patients.

\section{Population and Sample}

Samples were taken sequentially (consecutive sampling) in AMI patients with ST segment elevation myocardial infarction (STEMI) and Non ST segment elevation myocardial infarction (NSTEMI) beetwen March and May 2021. The patients were treated at the ICVCU Dr. Moewardi Hospital, Surakarta, and were willing to participate in this study and willing to be followed for the occurrence of MACE during hospitalization. MACEs during the hospitalization period were defined as the presence of at least one of the following events: death, cardiopulmonary resuscitation (CPR), cardiogenic shock, acute heart failure, stroke, major bleeding, and arrhythmias (sustained ventricular tachycardia, ventricular fibrillation.The inclusion criteria for this study sample were patients with AMI (based on complaints of chest pain accompanied by an increase in cardiac enzyme biomarkers both with ST-segment elevation and without ST-segment elevation). The exclusion criteria for this study were patients with malignancy, chronic renal failure, stroke and patients with severe sepsis. The definition of AMI was based on the fourth universal definition of myocardial infarction (2018) ESC/ACC/AHA/WHF Expert Consensus Document (Thygesen et al., 2018). 


\section{Study Variables}

The independent variable in this study was the level of copeptin and the dependent variable was MACE at the time of hospitalization. The criteria for MACE in this study were acute heart failure, cardiogenic shock, ventricular arrhythmias (which included ventricular fibrillation and ventricular tachycardia), cardiopulmonary resuscitation followed by return of spontaneous circulation, and death. Only the first event was included in the analyses of patients who experienced more than one event.

\section{Study Instruments}

Copeptin examination was carried out when the patient entered the Emergency room of Dr. Moewardi hospital. Blood samples were taken from the antecubital vein, using the closed suction method and placed in ethylenediaminetetra acetic acid (EDTA) tubes. Blood was centrifuged for 15 min at $5000 \mathrm{rpm}$ to obtain the serum. The blood serum was stored in a special tube and frozen at $-80^{\circ} \mathrm{C}$ until further examination. Copeptin examination was carried out at the Clinical Pathology Laboratory at Dr. Moewardi hospital.

\section{Data Analysis}

Continuous variables are presented as mean and standard deviation. Test the normality of the data distribution on continous variables with the Kolmogorov-Smirnov or Saphiro Wilk test. Chi-square test or Fisher's exact test is used to compare between 2 categorical variables. Pearson or Spearman correlation test is used to compare data between 2 numerical variables. Independent t-test or Mann Whitney test was used to compare data with categorical variables. The cut-point value for optimal copeptin levels to predict the occurrence of MACE was analyzed by receiver operating characteristic (ROC) curve. Copeptin levels are considered high if it is more than the cut-off point value and considered low if it was lower than the cutpoint value. The data were statistically analyzed using SPSS version 22.0 (IBM Corp., Armonk, NY, USA). $\mathrm{P}<0.05$ was considered statistically significant.

\section{Research Ethics}

The research ethics include inside informed consent, identity confidentiality, and ethical clearance carried out in the Dr. Moewardi hospital, Surakarta.

\section{RESULTS}

This study was conducted in the emergency room and ICVCU Dr. Moewardi hospital Surakarta in March to May 2021in 52 AMI patients, 44 people were males (84.6\%), and 8 females (15.4\%).STEMI as many as 41 people (78.8\%) and NSTEMI as many as 11 patients $(21.2 \%)$.The age of the patients ranged from $38-83$ years with a mean age of 60 years $(M e a n=60 ; S D=10)$. The sample was divided into 2 groups, namely those with MACE (MACE +) and those without MACE (MACE -). The basic characteristics of the patients are presented in Table 1.

Table 1. Description of sample characteristic (continuous data)

\begin{tabular}{lcccc}
\hline Variables & Mean & SD & Min. & Max. \\
\hline Copeptin levels $(\mathrm{pg} / \mathrm{mL})$ & $1,881.30$ & $1,059.26$ & 587.00 & $4,102.00$ \\
Age (year) & 60 & 10 & 38 & 83 \\
BMI $\left(\mathrm{kgBW} / \mathrm{m}^{2}\right)$ & 23.30 & 2.66 & 18.40 & 31.20 \\
Onset (hour) & 26.57 & 35.11 & 1.00 & 110.00 \\
\hline
\end{tabular}


Wasyanto et al./ Role of Copeptin in predicting of Major Adverse Cardiovascular Events

Table 2. Description of sample characteristics (categorical data)

\begin{tabular}{lcc}
\hline \multicolumn{1}{c}{ Variables } & n & \% \\
\hline MACE & 25 & 48.08 \\
Yes & 27 & 51.92 \\
No & & \\
Gender & 44 & 84.60 \\
Males & 8 & 15.40 \\
Females & & \\
Risk Factors & 27 & 51.90 \\
Hypertension & 34 & 65.40 \\
DM & 39 & 75.00 \\
Smoking & 15 & 28.80 \\
Dyslipidemia & & \\
AMI type & 41 & 78.80 \\
STEMI & 11 & 21.20 \\
NSTEMI & & \\
Therapy & 14 & 26.90 \\
Fibrinolitic & 18 & 34.60 \\
Primary PCI & & \\
\hline
\end{tabular}

Of the 52 AMI patients, it is known that a total of 27 patients experienced MACE (52\%), the remaining 25 patients were included in the group without MACE (48\%). During hospitalization, 27 patients developed MACE (52\%), with details for acute heart failure, cardiogenic shock, arrhythmias, cardiopulmonary resuscitation and mortality of 15 patients (28\%), 5 patients (10\%), 4 patients (8\%), 2 patients (4\%), and 1 patient ( $2 \%)$, respectively.

\section{MACE during Hospitalization}
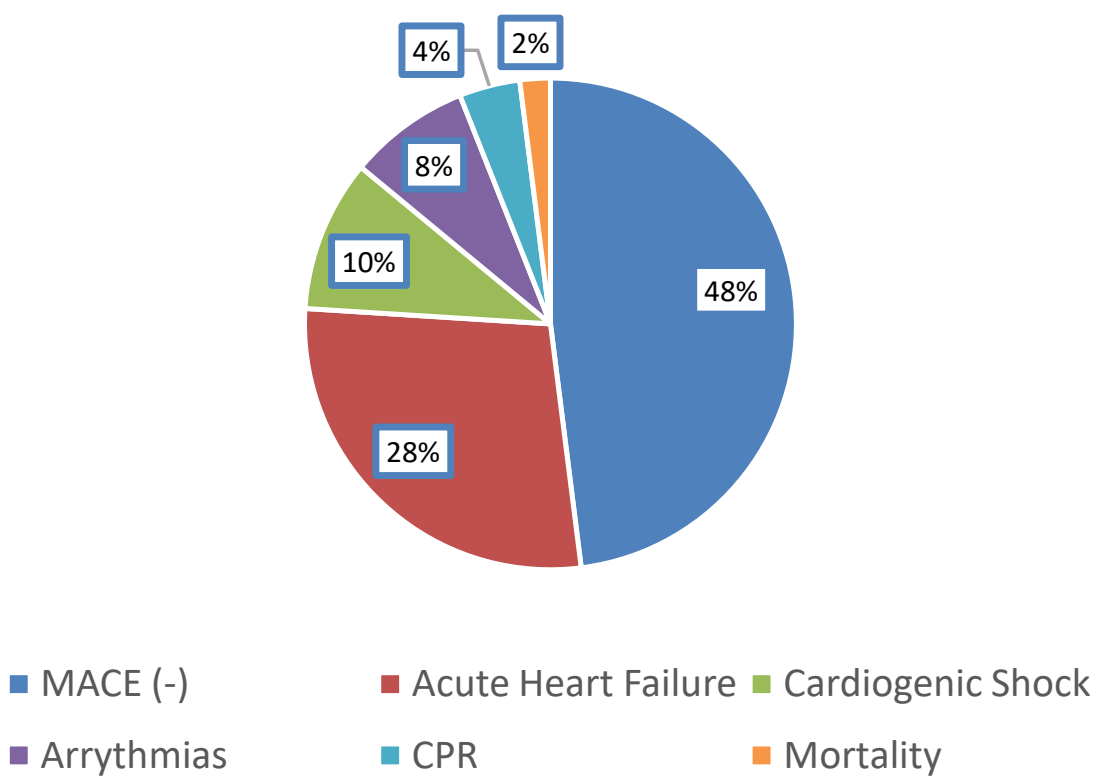

Figure 1. Proportion of MACE during hospitalization

Copeptin levels in general ranged from $587.00 \mathrm{pg} / \mathrm{mL}$ to $4102.00 \mathrm{pg} / \mathrm{mL}$, with an average value of $1,881.83 \mathrm{pg} / \mathrm{mL}$ (Mean $=1,881.83 ; \mathrm{SD}=1059.26)$. In the 
Wasyanto et al./ Role of Copeptin in predicting of Major Adverse Cardiovascular Events

non-MACE sample group, the values of copeptin levels ranged from $587.00 \mathrm{pg} / \mathrm{mL}$ to $3798.00 \mathrm{pg} / \mathrm{mL}$, with an average of $1,503.63 \mathrm{pg} / \mathrm{mL}$ (Mean= 1503.63; $\mathrm{SD}=$ 901.30). While in the sample group with

\section{Table 3. Description and testing of copeptin levels}

\begin{tabular}{cccc}
\hline Copeptin level & Mean & SD & p \\
\hline MACE $(\mathrm{pg} / \mathrm{mL})(-)$ & $1,503.63$ & 901.30 & 0.010 \\
MACE $(\mathrm{pg} / \mathrm{mL})(+)$ & $2,290.28$ & $1,081.26$ & \\
\hline
\end{tabular}

It was seen that the copeptin levels were higher in patients with MACE (Mean= 2,290.28; $\mathrm{SD}=1,081.26)$ than patients without MACE (Mean= 1,503.63; $\mathrm{SD}=$ 901.30), and it was statistically significant $(\mathrm{p}=0.010)$.

Testing of copeptin levels as a predicttor of the occurrence of MACE was carried
MACE, the value of copeptin levels ranged from $733.00 \mathrm{pg} / \mathrm{mL}$ to $4,102.00 \mathrm{pg} / \mathrm{mL}$, with an average of $2,290.28 \mathrm{pg} / \mathrm{mL}$ (Mean= 2,290.28; $\mathrm{SD}=1,081.26)$.

\section{ROC Curve}

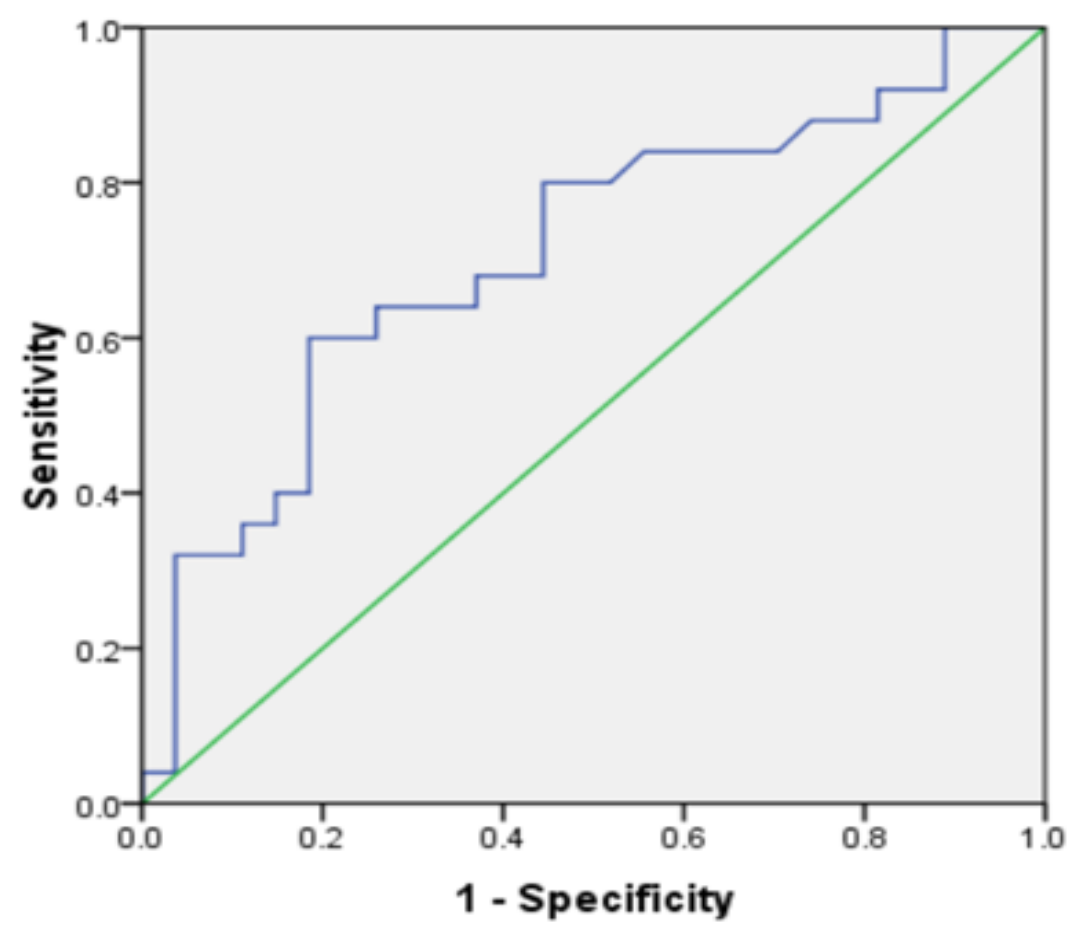

Figure 2. ROC curve for determining the cut-off point of the variable copeptin level on the incidence of MACE (cut-off point $=2,141.50 \mathrm{pg} / \mathrm{mL}$ ).

With a cut-off point for copeptin levels of $2141.50 \mathrm{pg} / \mathrm{mL}$, the occurrence of MACE can be detected from copeptin levels out using the ROC curve. The ROC curve for the occurrence of MACE (+) for copeptin levels as a predictor resulted in an area under curve (AUC) value of 0.71 .

Based on the ROC curve, the cut-off point value of copeptin was $2,141.50$ $\mathrm{pg} / \mathrm{mL}$. 
Wasyanto et al./ Role of Copeptin in predicting of Major Adverse Cardiovascular Events

calculating the sensitivity and specificity measures based on cross tabulation, it can also be used to analyze the qualitative relationship between copeptin levels and

Table 4. Calculation of sensitivity, specificity, diagnostic accuracy, and correlation of copeptin levels with MACE (cut-off point $=2,141.50 \mathrm{pg} / \mathrm{mL}$ )

\begin{tabular}{llcccc}
\hline \multirow{2}{*}{ Variable } & \multicolumn{2}{c}{ High Copeptin } & \multicolumn{2}{c}{ Low Copeptin } \\
\cline { 2 - 5 } & & n & \% & n & \% \\
\hline \multirow{2}{*}{ MACE } & Yes $(\geq 2141.50 \mathrm{pg} / \mathrm{mL})$ & 15 & 75.00 & 10 & 31.20 \\
& No $(<2141.50 \mathrm{pg} / \mathrm{mL})$ & 5 & 25.00 & 22 & 68.80 \\
\hline
\end{tabular}

The chi-square value of the relationship between copeptin levels and MACE was 9.437 with $\mathrm{p}=0.002$, meaning that the relationship between the two variables was significant. The odds ratio was 6.60 with 95\% CI 1.88 to 23.23 , indicating that the relationship between Copeptin levels and MACE was really significant. This shows
MACE using chi-square analysis. The calculation of the sensitivity, specificity and diagnostic accuracy can be seen in Table 4 .

Table 5. Multivariate analysis to predict MACE at hospitalization

\begin{tabular}{lccc}
\hline \multicolumn{1}{c}{ Variable } & OR & 95\% CI & p \\
\hline Copeptin & 7.55 & 1.47 to 38.94 & 0.016 \\
AMI & 16.92 & 1.47 to 194.19 & 0.023 \\
Primary PCI & 6.92 & 1.17 to 40.87 & 0.033 \\
DM (yes) & 5.95 & 1.05 to 33.71 & 0.044 \\
\hline
\end{tabular}

\section{DISCUSSION}

In recent years' clinical studies of AMI have increased with the discovery of new biomarkers, especially those that can detect early myocardial necrosis. These biomarkers can act as predictors and prognostics in patients with suspected ACS (Von Haehling et al., 2012). Assessment of plasma copeptin concentrations during hospitalization has been reported to be useful as a predicttor of major adverse cardiovascular events in AMI patients such as pulmonary embolism, multiple injuries and hemorrhagic or septic shock (Dieplinger et al., 2010). Other reported clinical events, with elevated Copeptin levels on admission, are: pulmonary disorders and cardiovascular disease as well as insulin resistance and metabolic syndrome (Enhorning et al., 2010).In our study, the occurrence of MACE during that the level of copeptin as a predictor of the occurrence of MACE is quite good.

A multivariate analysis was performed on the parameters that in the bivariate test showed significant statistics, namely copeptin, type of AMI, DM, and primary PCI measures for the occurrence of MACE during hospitalization (Table 5). 
stable angina) with the primary endpoint being a combination of major cardiovascular and cerebrovascular events within 3 months. The AUC value was 0.70 (95\% CI= 0.681-0.725) for the combination of major cardiovascular and cerebrovascular events after 3 months and the AUC value was 0.77 (95\% CI $=0.74$ to 0.80 ) for mortality (Von Haehling et al., 2012). The results of this study are in line with our research which proves that copeptin levels can act as predictors for major cardiovascular events during hospitalization, where the ROC curve for MACE events for the Copeptin variable as a predictor produces an AUC value of 0.710 with an accuracy rate of $71.15 \%$. This means that the variable levels of copeptin can detect the occurrence of MACE quite well.

Choi et al. (2018) in a retrospective study of 149 AMI patients who underwent successful PCI and measured copeptin levels to determine the subsequent occurrence of MACE. It was found that the incidence of MACE occurred at higher copeptin levels than those without MACE, in 34 (22.8\%) patients during a follow-up of 30.1 months. On multiple analysis logistic regression showed that increased copeptin levels were associated with the occurrence of MACE with $\mathrm{OR}=1.6, \mathrm{p}=0.005$. The results of this study are in line with our study which proves that copeptin levels can act as predictors for MACE during hospitalization with odds ratio $7.554, \mathrm{p}=0.016$. Our results strongly indicate that serum copeptin levels can serve as a prognostic marker and predicting MACE in patients with AMI during hospitalization.

MACE was observed only in the short term during hospitalization. Primary percutaneouscoronary intervention (Primary PCI) for AMI patients have not yet been fully implemented in our hospital, because of financial factors (i.e., lack of health insurance coverage), and high creatinine levels will affect the incidence of MACE.

Copeptin levels on admission to the hospital play a role as a predictor of the occurrence of MACE in AMI patients. Further research is needed to determine the optimal threshold for predicting MACE in AMI patients.

\section{AUTHOR CONTRIBUTION \\ I Putu Raynantha and Ahmad Yasa collected the data, recorded copeptin levels in the laboratory. Trisulo Wasyanto exa- mined clinical changes, check the occur- rence of MACE in all patients, did data analysis, and wrote the manuscript.}

\section{CONFLICT OF INTEREST}

No external funding and sponsorship.

\section{ACKNOWLEDGEMENT}

We would like to thank to Dr. Moewardi Hospital that give permission to collect the data.

\section{REFERENCE}

Braunwald E, Bonow RO, Mann DL, et al. (2019). Approaching to the patient with chest pain. In: Bonaca MS and Sabatine MS. Braunwald's Heart Diseases Textbook of Cardiovascular Medicine (11th Ed.). Philadelphia: Elsevier Saunders.

Choi HJ, Kim MC, Sim DS, Hong YJ, Kim JH, Jeong MH, Kim SH, et al. (2018). Serum copeptin levels predict clinical outcomes after successful percutaneous coronary intervention in patients with acute myocardial infarction. Ann Lab Med. 38(6): 538-544. https://doi.org/10.3343/alm.2018.38.6.53.

Dieplinger B, Gegenhuber A, Kaar G, Poelz W, Haltmayer M, Mueller T (2010). Prognostic value of established and novel biomarkers in patients with 
Wasyanto et al./ Role of Copeptin in predicting of Major Adverse Cardiovascular Events

shortness of breath attending an emergency department. Clin Biochem. 43(9): 714-719. https://doi.org/10.1016/j.clinbiochem.2010.02.0 02.

Enhörning S, Wang TJ, Nilsson PM, Almgren $\mathrm{P}$, Hedblad $\mathrm{B}$, Berglund $\mathrm{G}$, Struck J, et al. (2010). Plasma copeptin and the risk of diabetes mellitus. Circulation, 121(19): 2102-2108. https://dx.doi.org/10.1161\%2FCIRCU LATIONAHA.109.909663.

Katan M, Christ-Crain M (2010). The stress hormone copeptin: a new prognostic biomarker in acute illness. Swiss Med Wkly. 140(w13101): 1-6. https://doi.org/10.4414/smw.2010.13101.

Lattuca B, Sy V, Nguyen L, Bernard M, Zeitouni M, Overtchouk P, Yan Y, et al. (2019). Copeptin as a prognostic biomarker in acute myocardial infarction. Int J Cardiol, 274: 337-341. https://doi.org/10.1016/j.ijcard.2018. 09.022.

Lippi G, Plebani M, Somma SD, Monzani V, Tubaro M, Volpe M, Moscatelli P, et al. (2012). Considerations for early acute myocardial infarction rule-out for emergency department chest pain patients: the case of copeptin. Clin Chem Lab Med. 50(2): 243-253. https://doi.org/10.1515/cclm-2011o845.

Nickel CH, Bingisser R, Morgenthaler NG (2012). The role of copeptin as a diagnostic and prognostic biomarker for risk stratification in the emergency department. BMC Med. 10(7): 7-10. https://doi.org/10.1186/1741-701510-7.

Parizadeh SM, Ghandehari M, Parizadeh MR, Ferns GA, Ghayour-Mobarhan M, Avan A, Hassanian SM (2018). The diagnostic and prognostic value of copeptin incardiovascular disease, current status, and prospective. J Cell Biochem. 119(10): 7913-7923. https://doi.org/10.1002/jcb.27093.

Reichlin T, Hochholzer W, Stelzig C, Laule $\mathrm{K}$, Freidank H, Morgenthaler NG, Bergmann A, et al. (2009). Incremental value of copeptin for rapid rule out of acute myocardial infarction. J Am Coll Cardiol, 54(1): 60-68. https://doi.org/10.1016/j.jacc.2009.0 1.076.

Roth GA, Johnson C, Abajobir A, Abd-Allah F, Abera SF, Abyu G, Ahmed M, et al. (2017). Global, regional, and national burden of cardiovascular diseases for 10 causes, 1990 to 2015. J Am Coll Cardiol, 70(1): 1-25. https://doi.org/10.1016/j.jacc.2017.04.052.

Von Haehling S, Papassotiriou J, Morgenthaler NG, Hartmann O, Doehner W, Stellos K, Wurster T, et al. (2012). Copeptin as a prognostic factor for major adverse cardiovascular events in patients with coronary artery disease. Int J Cardiol. 162(1): 27-32. https://doi.org/10.1016/j.ijcard.2011. 12.105 .

Thygesen $K$ (2018). What's new in the Fourth Universal Definition of Myocardial infarction. Eur Heart J. 39 (42): 3757-3758. https://doi.org/10.1093/eurheartj/ehy655.

Urwyler SA, Schuetz P, Fluri F, Morgenthaler NG, Zweifel C, Bergmann A, Bingisser R, et al. (2010). Prognostic value of copeptin: one-year outcome in patients with acute stroke. Stroke. 41(7): 1564-1567. https://doi.org/10.1161/strokeaha.110.584649.

Virani SS, Alonso A, Aparicio HJ, Benjamin EJ, Bittencourt MS, Callaway CW, Carson AP, et al. (2021). Heart disease and stroke statistics-2021 update. Circulation. 143(1): e626- 
Wasyanto et al./ Role of Copeptin in predicting of Major Adverse Cardiovascular Events

e628. https://doi.org/10.1161/cir.ooo0000000000950.

Wasyanto T, Tridamayanti A (2019). Blood urea nitrogen as a predictor of in- hospital mortality in acute coronary syndrome patients. Indones $\mathrm{J}$ Med. 4(3): 241-251. https://doi.org/10.26911/theijmed.2019.04.03.07. 